\title{
RESEARCH
}

\section{LONG-TERM MEDICATION USE AND POLYPHARMACY IN OLDER ADULTS}

Turkish Journal of Geriatrics

DOI: 10.31086/tigeri.2021.207

2021; 24(2): 122-133

- Memet Taşkın EGici ${ }^{1}$

- Hasan BAĞCl${ }^{2}$

- Nermin GÜREL ${ }^{3}$

\section{CORRESPONDANCE}

\section{${ }^{1} \mathrm{Hasan} \mathrm{BAĞCI}$}

Yuksek Ithisas University, Faculty of Health Sciences, Department of Health Care Management, Ankara, Turkey

\section{Phone: +903124853718} e-mail: hasanbagci@gmail.com

Received: Mar 17, 2021

Accepted: May 21, 2021

1 University of Health Sciences Turkey, Haydarpasa Numune Training and Research Hospital, Department of Family Medicine, Istanbul, Turkey

2 Yuksek Ihtisas University, Faculty of Health Sciences, Department of Health Care Management, Ankara, Turkey

${ }^{3}$ University of Health Sciences Turkey, Istanbul Prof. Dr. Cemil Tascioglu City Hospital, Department of Pharmacology, İstanbul, Turkey

\section{Abstract}

Introduction: In Turkey, long-term medication use reports help patients covered by universal health insurance to access drugs without having to make co-payments. Using these reports, the present study investigates the prevalence of polypharmacy and specifically, its relationship with age, gender, diagnosis, number of diseases, and various clinical branches.

Materials and Methods: In this descriptive retrospective study, anonymous data obtained from long-term medication use reports were analyzed using SPSS and Microsoft Excel.

Results: A total of 66,995 samples were examined, $60.7 \%$ of which were female patients. The average number of active substances was $2.78 \pm 2.11$, the rate of reports containing five or more active substances (polypharmacy) was $16.1 \%$ (10.757 samples), the distribution by gender was $62.7 \%$ female and $37.3 \%$ male. The distribution of polypharmacy by age groups was $60.1 \%$ in the $65-74$ age group, $32.5 \%$ in the $74-85$ age group, and $7.4 \%$ in the $\geq 85$ age group. The most common diagnoses were diabetes mellitus (37.8\%), hypertension (12.9\%), and hyperlipidemia (8.2\%). The clinical branches accounting for the highest rate of polypharmacy were internal medicine $(65.1 \%)$, cardiology $(10 \%)$, and chest diseases (6.1\%). Acetylsalicylic acid was the most prescribed substance (12.3\%) among 657 active substances.

Conclusion: The results of this study can be used by regulatory authorities and in clinical practice by physicians. Using a clinical decision system supported by guidelines can help clinicians to optimize drug therapy and reduce polypharmacy in older adults. To reduce inappropriate drug use, such as the Beers, STOPP-START, and TIME criteria were recommended to be used in decision support systems.

Keywords: Aged; Chronic Diseases; Multimorbidity; Polypharmacy; Prescriptions 


\section{INTRODUCTION}

Life expectancy at birth has increased worldwide over the past 50 years owing to advances in the healthcare field and improved living standards. Consequently, the global population of older adults has also increased. In Turkey, individuals aged $\geq 65$ years constituted $9.5 \%$ of the total population in 2020. Moreover, between 2000 and 2020, whereas the country's total population increased by $25 \%$, the number of those aged $\geq 65$ years increased by $42 \%$ (1). Chronic diseases are becoming increasingly prevalent owing to the aging population and lifestyle changes. Moreover, it is now common for individuals to have two or more co-occurring chronic medical conditions, also known as multimorbidity (2).

The use of multiple medications, or polypharma$c y$, is common in older adults. Although there is no standard definition, polypharmacy is often referred to as the daily use of $\geq 5$ medications. This includes over-the-counter, prescription, and/or traditional and complementary medicines (3). The number of prescribed drugs is the most important predictor of inappropriate prescriptions or adverse medication events in older patients (4). Polypharmacy is associated with older age, multimorbidity, recent hospitalization, female sex, depression, and the number of physicians prescribing drugs (5). The issue of polypharmacy in older adults is becoming prevalent in most countries. This is a cause for concern given the observed association between polypharmacy and a broad spectrum of negative health outcomes, including drug-related problems, adverse medication events, physical and cognitive function decline, hospitalization, and increased mortality (6). Polypharmacy is one of the three key action areas of the third World Health Organization Global Patient Safety Challenge (7). It is imperative that patients adhere to the dosage and timing of their prescriptions and that costs are kept to a minimum for them to achieve the best results.
According to the Organisation for Economic Cooperation and Development's (OECD) Health at a Glance 2019 report, which considers data from 14 countries, the polypharmacy rates in older adults vary widely (as much as elevenfold). Turkey reports the lowest rates and Luxembourg the highest. The wide variation can partially be explained through the launch of targeted polypharmacy initiatives in some countries, including related policies on reimbursement and prescriptions (8).

\section{Long-term Medication Use Report System}

Long-term medication use reports prepared electronically by a specialist physician or board are transferred to the pharmacy using information and communication technologies and followed by the pharmacist. These reports are valid up to a maximum of two years and include details regarding the active substances, the amount of each active substance in the medication, and the daily dosages. The electronic prescription and drug report provisioning system operate as part of the web services of the Ministry of Health and the Social Security Institute in Turkey $(9,10)$.

Electronic medical records obtained from health services provided within the scope of universal health insurance are recorded in an electronic database called the Medula system. There are four basic sub-modules in the Medula system: Medula pharmacy, Medula optics, Medula doctor, and Medula hospital (10). E-pulse is a personal health record system through which all health information can be centrally managed and accessed. Physicians can access a patient's previous electronic medical records via the E-pulse mobile application after the patient's permission. The physician from the relevant clinical branch can prescribe the medicines included in the long-term medication use report. Further, family physicians can re-prescribe the medicines for a maximum of 3 months using the Family Medicine Information System (Figure 1). 
Figure 1. Schematic of Prescription and Long-term Medication Use Report Provisioning System*

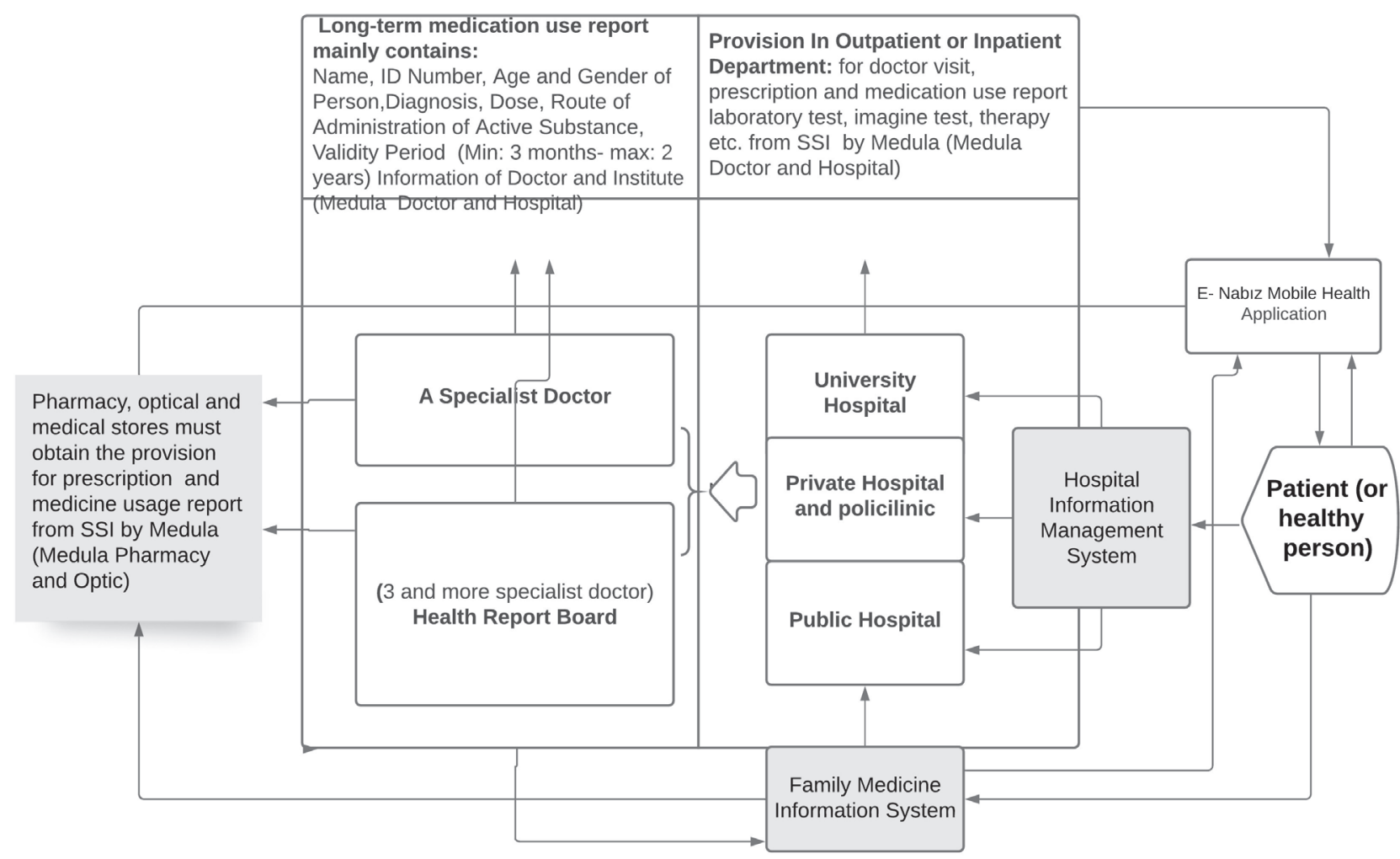

*(schematized by the authors)

The long-term medication use report system facilitates access to prescription medicines, as a significant proportion of the Turkish population is covered by social security. The Communiqué on the Healthcare Practices determines the payment methods for these drugs, with corresponding payment rules being created in the Medula information system. Additionally, there are no co-payments under the long-term medication use report system.

This study aims to generate insights for regulatory institutions by analyzing the number of drugs and diagnoses and their details in these reports. By ensuring that the reports are prepared based on scientific foundations and guidelines, it will be possible to prevent polypharmacy and inappropriate medicine use.

\section{MATERIALS AND METHODS}

This study retrospectively analyzed 2015-2016 data on the age, sex, diagnoses, and active substances, as available from the long-term medication use reports prepared by specialist physicians or health committees, for patients aged $\geq 65$ years. The analysis was conducted using the decision support feature of Istanbul's Region IV Public Hospitals Union's hospital information management system. Long-term medication use reports with similar content and for the same person were not included in the study results. Data from the reports were anonymized and examined after ethical approval was obtained from the İstanbul Prof. Dr. Cemil Taşcioglu City Hospital Clinical Research Ethics Committee (Approval number: 2020/572). 
Statistical analyses and calculations were performed using SPSS Statistics 26.0 (IBM Corp., Armonk, NY, USA) and Microsoft Excel 2013 (Microsoft Corp., Redmond, Washington, USA).

While evaluating the study data, frequencies (number, percentage) were used for categorical variables, and descriptive statistics (mean, standard deviation (SD), median (IQR-interquartile range)) for numerical variables. The differences between two independent groups were analyzed using the independent samples t-test.

Differences between more than two independent groups were analyzed using one-way analysis of variance (ANOVA). Tukey multiple comparison tests were used in cases where the one-way ANO$\checkmark A$ revealed a difference in group means. The relationships between independent numerical variables were checked with the Pearson correlation coefficient, while the relationships between categorical variables were checked using chi-square analysis. Statistical significance in the analysis was interpreted at the level of 0.05 .

\section{RESULTS}

The baseline data collected on each participant consisted of age, gender, all drugs (prescribed) with an ATC (anatomic therapeutic chemical) code fifth level, all diagnoses (using the international classification of diseases, 10 th revision (ICD-10) codes), relevant clinical branches, report date, report creator (specialist physician or board), and hospital name.

A total of 66,995 long-term medication use reports were analyzed, $60.7 \%$ of which concerned female patients. The average age in the reports was $74.22 \pm 6.96$ years. The mean age was $74.37 \pm 7.10$ years in the reports of female patients and $73.98 \pm$ 6.71 years in the reports of male patients. The age data, which are continuous in nature, were grouped as follows: $65-74,75-84$, and $85+$. We also found that $60.0 \%$ of the reports for patients between the ages of $65-74$ or $75-84$, and $67.8 \%$ of the reports for individuals aged $\geq 85$ years, were for women. There was a statistically significant difference $\left(x^{2}=140.121\right.$, $p<0.001$ ) between age groups in terms of gender.

The average number of diseases overall was $2.88 \pm 1.87$. The average number of diseases for females was $2.84 \pm 1.92$, and that for males was $2.93 \pm 1.76$. The average number of diseases was $2.86 \pm 1.86$ for patients aged $65-74$ years, $2.90 \pm 1.86$ for patients aged $75-84$, and $2.90 \pm 1.86$ for patients aged $\geq 85$ years. The proportion of individuals with multimorbidity (two or more diseases) was $67.3 \%$ across all age groups. Distribution of patients with multimorbidity by gender, $55.9 \%$ for women and $44.1 \%$ for men; The distribution by age groups is $56.1 \%$ for $65-74$ years, $34.8 \%$ for $75-84$ years, $9.1 \%$ for 85 years and over (Table 1). A statistically significant difference was found between diagnosis groups according to age groups and gender $x^{2}={ }_{\text {age }}$ groups 27.043, $p=0.001, x^{2}={ }_{\text {gender }} 2721.577, p<0.001$ ).

The most common diagnoses were hypertension (18.8\%), diabetes mellitus (14.8\%), hyperlipidemia (6\%), cancer (5\%), psychiatric disorders (4.4\%), heart diseases (4.4\%), and chronic obstructive pulmonary disease (3.3\%). The proportion of females was significantly higher in all diagnosis groups, except for cancer $(57.3 \%, n=1,915)$ and chronic ischemic heart disease $(52.1 \%, n=558)$, which were more prevalent among males.

The average number of active substances overall was $2.78 \pm 2.11$. The prevalence of polypharmacy overall was $16.1 \%(n=10,757)$. The average number of active substances for females was $2.80 \pm 2.06$, and that for males was $2.74 \pm 2.17$. The distribution of polypharmacy by gender was $62.7 \%$ female and $37.3 \%$ male. There was a statistically significant difference between men and women regarding the average number of active substances, based on the independent samples $t$-test $(t=-3.909, p<0.001)$ (Table 2).

The average number of active substances was $2.85 \pm 2.16$ in the $65-74$ year age group, 2.72 \pm 2.06 in the 75-84 year age group, and $2.54 \pm 1.95$ in the $\geq 85$ 
Table 1. Age Groups, Sex, and Number of Diagnoses in Long-term Medication Use Reports

\begin{tabular}{|c|c|c|c|c|c|c|}
\hline \multirow[b]{2}{*}{$\begin{array}{l}\text { Age groups } \\
\text { \& Gender }\end{array}$} & \multicolumn{4}{|c|}{ Percent and Number of Diagnosis } & \multirow[b]{2}{*}{$\begin{array}{c}\geq 5 \\
\mathrm{n}(\%)\end{array}$} & \multirow[b]{2}{*}{$\begin{array}{c}\text { Total } \\
\mathrm{n} \%\end{array}$} \\
\hline & $\begin{array}{c}1 \\
\text { n (\%) }\end{array}$ & $\begin{array}{c}2 \\
\text { n (\%) }\end{array}$ & $\begin{array}{c}3 \\
n(\%)\end{array}$ & $n(\%)^{4}$ & & \\
\hline \multicolumn{7}{|l|}{$65-74$} \\
\hline Female & $8,861(39.1)$ & $2,623(11.6)$ & $4,068(17.9)$ & $2,363(10.4)$ & $4,754(21.0)$ & $22,669(100.0)$ \\
\hline Male & $3,657(24.2)$ & $3,881(25.7)$ & $2,996(19.8)$ & $1,503(9.9)$ & $3,079(20.4)$ & $15,116(100.0)$ \\
\hline Total & $12,518(33.1)$ & $6,504(17.2)$ & $7,064(18.7)$ & $3,866(10.3)$ & $7,833(20.7)$ & $37,785(100.0)$ \\
\hline \multicolumn{7}{|l|}{$75-84$} \\
\hline Female & $5,123(36.9)$ & $1,668(12.0)$ & $2,479(17.9)$ & $1,598(11.5)$ & $3,010(21.7)$ & $13,878(100.0)$ \\
\hline Male & $2,291(24.9)$ & $2,351(25.5)$ & $1,782(19.3)$ & $899(9.8)$ & $1,894(20.5)$ & $9,217(100.0)$ \\
\hline Total & $7,414(32.2)$ & $4,019(17.4)$ & $4,261(18.4)$ & $2,497(10.8)$ & $4,904(21.2)$ & $23,095(100.0)$ \\
\hline \multicolumn{7}{|l|}{$\geq 85$} \\
\hline Female & $1,525(36.8)$ & $494(11.9)$ & $751(18.1)$ & $482(11.7)$ & $893(21.5)$ & $4,145(100.0)$ \\
\hline Male & $469(23.8)$ & $474(24.1)$ & 408 (20.7) & 233 (11.8) & $386(19.6)$ & $1,970(100.0)$ \\
\hline Total & $1,994(32.6)$ & $968(15.8)$ & $1,159(19.0)$ & 715 (11.7) & 1,279 (20.9) & $6,115(100.0)$ \\
\hline Total Female & $15,509(38.1)$ & 4,785 (11.8) & 7,298 (17.9) & $4,443(10.9)$ & $8,657(21.3)$ & $40,692(100.0)$ \\
\hline Total Male & 6,417 (24.4) & $6,706(25.5)$ & $5,186(19.7)$ & $2,635(10.0)$ & $5,359(20.4)$ & 26,303 (100.0) \\
\hline Total & $21,926(32.7)$ & $11,491(17.2)$ & $12,484(18.6)$ & $7,078(10.6)$ & $14,016(20.9)$ & 66,995 (100.0) \\
\hline
\end{tabular}

year age group. As a result of the one-way analysis of variance (ANOVA) applied, the average active substance according to age groups was showed a statistically significant difference $(F=71.801, p$ $<0.001$ ). Polypharmacy was found in $60.1 \%$ of the cases in the $65-74$ age group, $32.5 \%$ of the cases in the 75-84 age group, and $7.4 \%$ of the cases in the $\geq 85$ age group. The use of $\geq 5$ active substances was most prevalent in the 65-74 year age group (Table 2). The active ingredient average was $2.84 \pm$ 2.24 in 1 disease, $2.74 \pm 2.05$ in 2 diseases, $2.72 \pm$
2.04 in 3 diseases, $2.72 \pm 1.96$ in 4 diseases, and 2.79 \pm 2.06 in $\geq 5$ diseases. As a result of the one-way analysis of variance (ANOVA) applied, the average active substance according to the number of diseases was showed a statistically significant difference ( $F=65.659, p<0.001)$. According to the number of diseases, the rate of polypharmacy is $34.1 \%$ in 1 disease, $15.9 \%$ in 2 diseases, $18.1 \%$ in 3 diseases, $10.6 \%$ in 4 diseases, and $21.3 \%$ in $\geq 5$ diseases (Table 2). 
Table 2. Age Groups, Gender, Number of Diseases, and the Prevalence of Polypharmacy ( $\left.{ }^{\star} p<0.05\right)$

\begin{tabular}{|c|c|c|c|c|c|}
\hline \multirow{2}{*}{ Baseline characteristics } & \multicolumn{3}{|c|}{ Number of Drugs } & \multicolumn{2}{|c|}{ Polypharmacy ( $\geq 5$ drugs) } \\
\hline & Mean \pm SD & Median (IQR) & $\begin{array}{c}\text { Statistical } \\
\text { Test }\end{array}$ & $\mathbf{N}$ & $\%$ \\
\hline Total & $2.78 \pm 2.11$ & $2.0(3.0)$ & & 10,757 & $16.1 \%$ \\
\hline \multicolumn{6}{|l|}{ Gender } \\
\hline Men & $2.74 \pm 2.17$ & $2.0(2.0)$ & \multirow{2}{*}{$\begin{array}{c}t=-3.909 \\
p=0.000 *\end{array}$} & 4,017 & $15.3 \%$ \\
\hline Women & $2.80 \pm 2.06$ & $2.0(3.0)$ & & 6.740 & $16.6 \%$ \\
\hline \multicolumn{6}{|l|}{ Age Groups } \\
\hline $65-74$ & $2.85 \pm 2.16$ & $2.0(3.0)$ & \multirow{3}{*}{$\begin{array}{l}F=71.801 \\
p=0.000^{\star}\end{array}$} & 6,460 & $17.1 \%$ \\
\hline $74-85$ & $2.72 \pm 2.06$ & $2.0(2.0)$ & & 3,496 & $15.1 \%$ \\
\hline$\geq 85$ & $2.54 \pm 1.95$ & $2.0(2.0)$ & & 801 & $13.1 \%$ \\
\hline \multicolumn{6}{|l|}{ Number of Diseases } \\
\hline 1 & $2.84 \pm 2.24$ & $2.0(3.0)$ & \multirow{5}{*}{$\begin{array}{l}F=65.659 \\
p=0.000 *\end{array}$} & 3,664 & $16.7 \%$ \\
\hline 2 & $2.74 \pm 2.05$ & $2.0(2.0)$ & & 1,713 & $14.9 \%$ \\
\hline 3 & $2.72 \pm 2.04$ & $2.0(3.0)$ & & 1,948 & $15.6 \%$ \\
\hline 4 & $2.72 \pm 1.96$ & $2.0(3.0)$ & & 1,140 & $16.1 \%$ \\
\hline$\geq 5$ & $2.79 \pm 2.06$ & $2.0(3.0)$ & & 2,292 & $16.3 \%$ \\
\hline
\end{tabular}

Specialists from 15 different departments made the diagnoses. A majority of the long-term medication use reports were prepared by the department of internal medicine, at $39.3 \%(n=26,345)$; followed by cardiology at $11.1 \%(n=7,443)$ and neurology at $10.6 \%(n=7,078)$. The average number of active substances in the reports prepared by the departments of medical oncology, internal medicine, and radiation oncology was $4.91 \pm 4.98,3.40 \pm 2.40$, and $3.24 \pm 3.33$ respectively. The reports prepared by these departments had higher average numbers of active substances than those prepared by the other clinical branches. In Table 3, the results of the oneway ANOVA revealed that there was a statistically significant difference in the average number of active substances in reports prepared by each clinical branch ( $F=593.269, p<0.001)$. The three most common branches in those with polypharmacy are Internal Medicine (65.1\%), Cardiology (10.0\%), and Chest Diseases (6.1\%).

When Table 4 is examined, the average number of active substances in patients with diabetes mellitus, cancer, and hyperlipidemia was $4.25 \pm 2.35$, $3.64 \pm 3.98$, and $3.11 \pm 1.90$, respectively. A one-way 
Table 3. Clinical Branches and Prevalence of Polypharmacy ( $p<0.05)$

\begin{tabular}{|c|c|c|c|c|c|}
\hline \multirow{2}{*}{ Clinical Branches } & \multicolumn{3}{|c|}{ Number of Drugs } & \multicolumn{2}{|c|}{ Polypharmacy ( $\geq 5$ drugs) } \\
\hline & Mean \pm SD & Median (IQR) & Statistical Test & $\mathbf{N}$ & $\%$ \\
\hline 1. Internal Medicine & $3.40 \pm 2.40$ & $3.0(3.0)$ & \multirow{15}{*}{$\begin{array}{l}F=593.269 \\
p=0.000 *\end{array}$} & 6,999 & $65.1 \%$ \\
\hline 2. Cardiology & $2.66 \pm 1.64$ & $2.0(3.0)$ & & 1,071 & $10.0 \%$ \\
\hline 3. Chest Diseases & $3.07 \pm 1.54$ & $3.0(2.0)$ & & 660 & $6.1 \%$ \\
\hline 4. Neurology & $2.14 \pm 1.42$ & $2.0(2.0)$ & & 463 & $4.3 \%$ \\
\hline 5. Medical Oncology & $4.91 \pm 4.98$ & $2.0(6.0)$ & & 381 & $3.5 \%$ \\
\hline 6. Physical Treatment\&Rehabilitation & $2.54 \pm 1.31$ & $2.0(1.0)$ & & 299 & $2.8 \%$ \\
\hline 7. Radiation Oncology & $3.24 \pm 3.33$ & $2.0(3.0)$ & & 187 & $1.7 \%$ \\
\hline 8. Orthopedics \& Traumatology & $2.23 \pm 1.29$ & $2.0(1.0)$ & & 130 & $1.2 \%$ \\
\hline 9. Family Medicine & $2.32 \pm 1.71$ & $2.0(2.0)$ & & 94 & $0.9 \%$ \\
\hline 10. Cardiovascular Surgery & $2.07 \pm 1.48$ & $1.0(2.0)$ & & 91 & $0.8 \%$ \\
\hline 11. General Surgery & $1.98 \pm 1.57$ & $1.0(1.0)$ & & 65 & $0.6 \%$ \\
\hline 12. Psychiatry & $1.90 \pm 0.91$ & $2.0(1.0)$ & & 33 & $0.3 \%$ \\
\hline 13. Ophthalmology & $1.85 \pm 0.74$ & $2.0(1.0)$ & & 19 & $0.2 \%$ \\
\hline 14. Urology & $1.54 \pm 0.68$ & $1.0(1.0)$ & & 14 & $0.1 \%$ \\
\hline 15. Other & $2.54 \pm 2.04$ & $2.0(2.0)$ & & 251 & $2.3 \%$ \\
\hline
\end{tabular}

ANOVA revealed a statistically significant difference in the average number of active substances according to the diagnoses ( $F=579.872, p<0.001$ ), ( $T a-$ ble 4). The most prevalent diagnoses in individuals with $\geq 5$ active substances were diabetes mellitus (37.8\%), hypertension (12.9\%), and hyperlipidemia (8.2\%).

There were 183,667 active substances mentioned in the reports. The reports also included non-pharmaceutical materials used in chronic disease man- agement, such as needle tips and blood-sugar measuring sticks. Only prescription drugs specified in the Social Security Institution payment list were included in this study, yielding a total of 657 active substances. The most prescribed active substance was acetylsalicylic acid (prescribed 8,245 times), followed by biguanides $(6,589)$, beta-blocking agents $(6,267)$, HMG CoA reductase inhibitors (statins; $6,115)$, calcium channel blockers $(3,868)$, and angiotensin-converting enzyme (ACE) inhibitors $(3,294)$. 
Table 4. Diagnoses and Prevalence of Polypharmacy ( $p<0.05)$

\begin{tabular}{|c|c|c|c|c|c|}
\hline \multirow{2}{*}{ Diagnoses } & \multicolumn{3}{|c|}{ Number of Drugs } & \multicolumn{2}{|c|}{ Polypharmacy ( $\geq 5$ drugs) } \\
\hline & Mean \pm SD & Median (IQR) & Statistical Test & $\mathbf{N}$ & $\%$ \\
\hline 1. Diabetes Mellitus & $4.25 \pm 2.35$ & $4.0(4.0)$ & \multirow{15}{*}{$\begin{array}{l}F=579,872 \\
p=0.000 *\end{array}$} & 4,064 & $37.8 \%$ \\
\hline 2. Hypertension & $2.48 \pm 1.71$ & $2.0(2.0)$ & & 1,388 & $12.9 \%$ \\
\hline 3. Hyperlipidemia & $3.11 \pm 1.90$ & $3.0(3.0)$ & & 884 & $8.2 \%$ \\
\hline 4. Cancer & $3.64 \pm 3.98$ & $2.0(3.0)$ & & 706 & $6.6 \%$ \\
\hline 5. Atrial fibrillation and flutter & $2.47 \pm 1.85$ & $2.0(2.0)$ & & 284 & $2.6 \%$ \\
\hline 6. Chronic obstructive lung disease & $2.37 \pm 1.93$ & $2.0(2.0)$ & & 280 & $2.6 \%$ \\
\hline 7. Depressive episode & $2.40 \pm 1.46$ & $2.0(2.0)$ & & 178 & $1.7 \%$ \\
\hline 8. Chronic ischemic heart disease & $2.18 \pm 1.75$ & $1.0(2.0)$ & & 114 & $1.1 \%$ \\
\hline 9. Glaucoma & $2.25 \pm 1.63$ & $2.0(2.0)$ & & 108 & $1.0 \%$ \\
\hline 10. Retinal deterioration & $2.39 \pm 1.68$ & $2.0(2.0)$ & & 92 & $0.9 \%$ \\
\hline 11. Anxiety disorders & $2.52 \pm 1.38$ & $2.0(1.0)$ & & 48 & $0.4 \%$ \\
\hline 12. Asthma & $1.97 \pm 1.42$ & $2.0(1.0)$ & & 41 & $0.4 \%$ \\
\hline 12. Dementia in Alzheimer's Disease & $1.95 \pm 1.04$ & $2.0(1.0)$ & & 17 & $0.2 \%$ \\
\hline 14. Nonorganic psychosis & $1.86 \pm 1.09$ & $2.0(2.0)$ & & 10 & $0.1 \%$ \\
\hline 15. Other & $2.40 \pm 1.72$ & $2.0(2.0)$ & & 2,543 & $23.6 \%$ \\
\hline
\end{tabular}

\section{DISCUSSION}

A previous study of 17 European countries and Israel used data for participants aged $\geq 65$ years from Wave 6 of the Survey of Health, Aging, and Retirement in Europe database. In that study, the prevalence of polypharmacy in each country ranged from $26.3 \%$ to $39.9 \%$. Polypharmacy prevalence was lower in Switzerland (26.3\%), Croatia (27.3\%), and Slovenia (28.1\%), and higher in Portugal (36.9\%), Israel (37.5\%), and the Czech Republic (39.9\%) (11).
OTC drugs, vitamins, and minerals were included in this study, conducted with 10,989 people aged $\geq 65$ years. It is noteworthy that the polypharmacy rate in Turkey is remarkably lower than in OECD countries (8). In terms of multiple medication use, $16.1 \%$ of the patients in this study used $\geq 5$ medications, it is seen that the prevalence of polypharmacy is quite low compared to European countries. The exclusion of OTC and similar food supplements plays an important role in our study. 
A previous study in Germany included patients aged over 60 years who had made at least one visit to any of the 1,010 general practitioners between January to June 2017-yielding a sample of 564,352 patients for analysis. Of these patients, $85 \%$ of males and $86 \%$ of females showed multimorbidity. Simultaneously, $38 \%$ of males and $37 \%$ of females met the criteria for polypharmacy. The mean number of chronic diseases was $5.3(S D=4.4)$ in males and $5.7(S D=4.6)$ in females. The mean number of prescribed medications was $4.2(\mathrm{SD}=2.7)$ in both males and females (12). By contrast, our study found that the average number of chronic diseases in Turkish patients aged $\geq 65$ years was overall $2.88 \pm 1.86$ and multimorbidity was found overall $67.3 \%$. The average number of active substances used by females was $2.80 \pm 2.06$, whereas the number was $2.74 \pm 2.17$ for males. The prevalence of polypharmacy in the primary care study in Germany was much higher than in our study.

Data obtained from the Irish Longitudinal Study on Aging showed that $27 \%$ of the $\geq 54$ year age group used $\geq 5$ medications (13). Similarly, in Sweden, out of 1,742,336 individuals aged $\geq 65$ years who were included at baseline in a prospective cohort study, $44 \%$ were exposed to polypharmacy ( $\geq 5$ medications) and used 4.6 different drugs on average (14). Thus, the prevalence of polypharmacy is high among older adults in Ireland and Sweden. Contrastingly, $16.1 \%$ of the patients used $\geq 5$ medications and the average number of active substances was $2.78 \pm 2.11$ in Turkey.

In another survey in Spain of 164,513 patients with multimorbidity and aged $>65$ years, the 65-79 year age group was prescribed a median of four medications. The 80-94 years age group was prescribed a median of six medications. At least $45.9 \%$ of the 65-79 year age group and $61.8 \%$ of the $80-94$ year age group were prescribed $\geq 5$ medications (15). In our study, the average number of active substances was $2.85 \pm 2.16$ in the 65-74 years age group, 2.72 \pm 2.06 in the $75-84$ years age group, and
$2.54 \pm 1.95$ in the $\geq 85$ years age group.

In a study of 1,003 patients in France, polypharmacy (5 to 9 medications) and excessive polypharmacy ( $\geq 10$ medications) were reported in $42.9 \%$ and $27.4 \%$ of the study cohort, respectively (16). The prevalence of polypharmacy overall was $16.1 \%$ ( $n=$ $10,757)$ in our study. Thus, the prevalence of polypharmacy in France is almost three times higher than in this study.

A study conducted by Qato et al. used cross-sectional data from a nationally representative of 2,206 United States citizens. The mean age was 71.4 years, and $51.6 \%$ of the sample consisted of females. That study found that nearly $87.7 \%$ of the subjects used at least one prescription medicine, while $35.8 \%$ simultaneously used five or more prescription medications. The use of multiple medications increased from 2005 to 2011, particularly the use of statins (33.8\% to $46.2 \%)$, acetylsalicylic acid $(30.2 \%$ to $40.2 \%)$, and proton pump inhibitors (15.7\% to $18.5 \%)$. The use of antihypertensives increased slightly (60.9\% to $65.1 \%)$, primarily driven by increases in the use of angiotensin-converting enzyme inhibitors (24.5\% to $30.4 \%$ ), which are commonly used as diuretics (29.5\%) and ?-blockers (31.2\%) (17). In the present study, only $16.1 \%$ of the patients aged $\geq 65$ years received prescriptions containing $\geq 5$ drugs. The most commonly prescribed drugs in our study were similar to those in the USA. Acetylsalicylic acid (12.3\%) was the most prescribed active substance, followed by biguanides (9.8\%), beta-blocking agents (9.3\%), statins (9.1\%), calcium channel blockers (5.7\%), and ACE inhibitors (4.9\%).

One Canadian study found that, in 2016, approximately one-third (35.3\%) of Canadian older adults were chronically using $\geq 5$ medications from different medication classes, and 1 out of 18 (5.5\%) were chronically using medications from 10 or more different medication classes. Statins were the most common medication class used by nearly half of all older adults (46.6\%). The next most commonly used medication classes were ACE inhibitors-used to 
treat high blood pressure and heart failure-and proton pump inhibitors-used to treat gastroesophageal reflux and peptic ulcer disease-used by $28.2 \%$ and $26.9 \%$ of older adults, respectively (18). In terms of multiple medication use, $16.1 \%$ of patients were using $\geq 5$ medications in our study. Based on these findings, it can be concluded that, compared to our study, polypharmacy in Canada and the USA are twice as high and the most common medications are generally similar to those covered in Canada and USA studies.

A previous study examined the electronic prescriptions prepared in 2018 by family physicians across Turkey for geriatric patients (aged $\geq 65$ years), based on the prescription information system. In this geriatric cohort, 6,104,798 individuals (85.0\%) had at least one prescription. Moreover, $14.3 \%$ of the patients were chronically prescribed $\geq 5$ medications. Additionally, the percentage of those with polypharmacy ranged between 16.4\% and $20.7 \%$. Each prescription contained an average of 2.9 individual drug items, and each medication was prescribed in 2.7 boxes on average (19). The prevalence of polypharmacy in this study, which was conducted with the data obtained from the family medicine information system, was found to be very close to the findings of our study. There was a difference between the drugs prescribed to patients examined in primary care and the long-term drug use reports in our study.

Polypharmacy in older adults requires more attention because of age-related changes in pharmacokinetics and pharmacodynamics, exclusion of these patients from clinical studies, inadequate representation in guidelines, excessive morbidity, the effect of dementia on the course and management of diseases, and poor communication. In the case of such patients, other chronic conditions and their medication use must be thoroughly assessed when taking their medical history (anamnesis), because a detailed evaluation can reduce the number of medications used. When medication is prescribed, interaction with other existing medications and aging-related factors must be considered.

There are several ways to prevent polypharmacy. Two major approaches to minimize the adverse outcomes of multiple medication use are i) using computerized doctor prescriptions that feature clinical decision support systems based primarily on guidelines on the prescribing process and interventions, and ii) establishing examination processes after computer-assisted or non-computer-assisted prescriptions (20). Bates et al. defined computerized decision support systems as computer-based systems providing "passive and active referential information as well as reminders, alerts, and guidelines" (21). Automated decision support system tools consistently reduce the number of potentially inappropriate prescriptions started and the mean number of potentially inappropriate prescriptions per patient. These tools also increase potentially inappropriate prescription discontinuation and medication appropriateness (22).

The Screening Tool of Older Persons' Prescriptions (STOPP) and the Screening Tool to Alert to Right Treatment (START) are explicit criteria that facilitate medication review in multimorbid older adults in most clinical settings. Electronic deployment of the STOPP/START criteria is a significant technical challenge; however, recent clinical trials of software prototypes have demonstrated their feasibility (23). The SENATOR and OPERAM trials are ongoing multicenter randomized controlled trials currently being conducted across Europe. These trials employ computerized versions of STOPP and START in their interventions (24).

Prescribing habits and locally available medications vary considerably between countries, and the evidence on appropriate prescriptions for older persons continues to evolve. Within this context, the Turkish Inappropriate Medication Use in the Elderly (TIME) criteria set (TIME-to-STOP/ TIME-toSTART) — produced under the leadership of the Rational Drug Use Working Group of the Turkish Aca- 
demic Geriatrics Society_provides a guide tailored to the specific needs of the Turkish people as well as an explicit screening tool (25).

Computerized interventions have been suggested as an effective strategy to improve prescription appropriateness for hospitalized older adults. In the hospital setting, the electronic prescribing and computerized physician order entry (CPOE) systems have reduced prescribing errors and help prevent adverse drug events (24). A long-term medication use report system designed similarly, with international medicine usage instructions such as the Beers, STOPP-START, and TIME criteria, would encourage rational medicine use. Future research should continue to focus on evaluating the use of Medula and clinical decision-making system to reduce inappropriate prescribing and polypharmacy in older people.

The study's main limitation was that only longterm medication use reports by specialist physicians or boards were analyzed. Thus, prescriptions without reports written by specialist physicians and

\section{REFERENCES}

1. Turkish Statistical Institute. The Results of Address Based Population Registration System, 2020 [e-newsletter] TUiK Publication; 2021. [Internet]. Available from: https://data.tuik.gov.tr/Bulten/ Index? $p=$ The-Results-of-Address-Based-Population-Registration-System-2020-37210\&dil=2 Accessed: 16.03.2021

2. World Health Organization. Multimorbidity [e-book] World Health Organization; 2016. [Internet]. Available from: https://apps.who.int/iris/bitstream/ha ndle/10665/252275/9789241511650-eng.pdf?sequence=1. Accessed: 16.03.2021

3. World Health Organization. Medication Safety in Polypharmacy [e-book] World Health Organization; 2019. [Internet]. Available from: https://apps.who. int/iris/bitstream/handle/10665/325454/WHO-UHCSDS-2019.11-eng.pdf?ua=1. Accessed: 16.03.2021

4. Scott IA, Hilmer SN, Reeve E, et al. Reducing inappropriate polypharmacy: the process of deprescrib- family physicians, as well as OTC medications and dietary supplements obtained from pharmacies without a prescription, were not included in this study.

Re-prescribed data with similar content for the same person in long-term drug use reports were not included in the study results. On the other hand, data from the same person with different diagnoses from different clinical branches were included.

\section{Acknowledgments}

We thank Emre Yasar and Ömer Kaplan for statistical support and Cumali Celik, Meral Kok Can and Hatem Karapinar for their technical contributions to the data.

\section{Conflict of Interest}

The authors declare no potential conflicts of interest concerning the research, authorship, or publication of this article.

ing. JAMA Internal Medicine 2015 May;175(5):82734. (PMID: 25798731).

5. Pitkala, K.H., Strandberg, T.E. \& Tilvis, R.S. Is It Possible to Reduce Polypharmacy in the Elderly? Drugs \& Aging 2001; 18, 143-149. (PMID: 11346128)

6. Wastesson JW, Morin L, Tan ECK, Johnell K. An Update on the Clinical Consequences of Polypharmacy in Older Adults: A Narrative Review. Expert Opinion on Drug Safety 2018;17(12):1185-1196. (PMID: 30540223)

7. World Health Organization. Medication Without Harm - Global Patient Safety Challenge on Medication Safety [e-book] World Health Organization; 2017. [Internet]. Available from: https://apps.who. int/iris/bitstream/handle/10665/255263/WHO-HISSDS-2017.6-eng.pdf Accessed: 16.03.2021

8. Organisation for Economic Cooperation and Development (OECD). Health at a Glance 2019: OECD Indicators, [e-book] OECD Publishing, 2020. [Internet]. Available from: https://www. 
oecd-ilibrary.org/docserver/4dd50c09-en.pdf?expires $=1616007583 \& i d=i d \& a c c n a m e=$ guest $\&$ check sum $=03 F 2 D 5 B 6138 A 0347621735 B E 132 B 14 F 4 \quad A c-$ cessed: 16.03.2021

9. Ministry of Health Health Services General Directorate Social Security Applicatıons Department. Directive on the Procedures and Principles of Health Reports. MoH;2020 [Internet]. Available from: https://shgmsgudb.saglik.gov.tr/Eklenti/39138/0/ yonerge-onaypdf.pdf Accessed: 16.03.2021.

10. Communiqué on Healthcare Practices of Social Security Institute -Official Gazette: Date:24.03.2013, Number:28597 [Internet]. Available from: https://www. resmigazete.gov.tr/eskiler/2013/03/20130324-3.pdf Accessed: 16.03.2021

11. Midão L, Giardini A, Menditto E, Kardas P, Costa E. Polypharmacy prevalence among older adults based on the survey of health, ageing, and retirement in Europe. Archives of Gerontology and Geriatrics 2018; 78:213-20. (PMID: 30015057).

12. Kostev K, Jacob L. Multimorbidity and polypharmacy among elderly people followed in general practices in Germany. European Journal of Internal Medicine 2018;55:66-8. (PMID: 30025890)

13. The Irish Longitudinal Study on Ageing. Health and Wellbeing: Active Ageing for Older Adults in Ireland [e-book] TILDA; 2017. [Internet]. Available from: https://www.atlanticphilanthropies.org/wp-content/ uploads/2017/03/TILDA-Wave-3-Key-Findings-report.pdf Accessed: 16.03.2021

14. Morin L, Johnell K, Laroche M-L, Fastbom J, Wastesson JW. The epidemiology of polypharmacy in older adults: register-based prospective cohort study. Clin Epidemiol 2018; 10:289-298. (PMID: 29559811)

15. Guisado-Clavero, M., Violán, C., López-Jimenez, T. et al. Medication patterns in older adults with multimorbidity: a cluster analysis of primary care patients. BMC Fam Pract 2019; 20, 82 (PMID: 31195985).

16. Herr M, Sirven N, Grondin H, Pichetti S, Sermet C. Frailty, Polypharmacy, and Potentially Inappropriate Medications in Old People: Findings in a Representative Sample of the French Population. Eur J Clin Pharmacol. 2017;73(9):1165-1172. (PMID: 28601963).

17. Qato DM, Wilder J, Schumm LP, Gillet V, Alexander GC. Changes in Prescription and Over-the-Counter
Medication and Dietary Supplement Use Among Older Adults in the United States, 2005 vs 2011. JAMA Intern Med. 2016;176(4):473-482. (PMID: 26998708).

18. Canadian Institute for Health Information. Drug Use Among Seniors in Canada, 2016. [e-book] ON: ClHI; 2018. [Internet]. Available from: https://www.cihi.ca/ sites/default/files/document/drug-use-among-seniors-2016-en-web.pdf Accessed: 16.03.2021

19. Aydos TR, Emre Aydıngöz S, Lux KM. et al. Polypharmacy Prevalence Among Geriatric Patients in Primary Healthcare Settings Across Turkey: a Cross-Sectional Analysis Through the Nationwide Prescription Information System. Turkish Journal of Geriatrics 2020; 23(2): 169-179 (DOI: 10.31086/tjgeri.2020.151).

20. Mair A, Fernandez-Llimos F, SIMPATHY Consortium. Polypharmacy management programmes: the SIMPATHY Project. Eurepean Journal of Hospital Pharmacy 2017;24(1):5-6. (PMID: 31156889)

21. David W. Bates, Gilad J. Kuperman, Samuel Wang et al. Ten Commandments for Effective Clinical Decision Support: Making the Practice of Evidence-based Medicine a Reality, Journal of the American Medical Informatics Association, 2003; 10 (6): 523-530,( PMID: 12925543).

22. Monteiro L, MD, Maricoto T, Solha I, et al. Reducing Potentially Inappropriate Prescriptions for Older Patients Using Computerized Decision Support Tools: Systematic Review. Journal of Medical Internet Research. 2019: 21(11): (PMID: 31724956)

23. O'Mahony D, STOPP/START Criteria for Potentially Inappropriate Medications/Potential Prescribing Omissions in Older People: Origin and Progress, Expert Review of Clinical Pharmacology 2020; 13:1, 15-22, (PMID: 31790317).

24. Dalton K, O'Brien G, O'Mahony D, Byrne S, Computerised Interventions Designed to Reduce Potentially Inappropriate Prescribing in Hospitalised Older Adults: A Systematic Review and Meta-analysis, Age and Ageing 2018; 47 (5), 670-678, (PMID: 29893779).

25. Bahat $G$, Ilhan B, Erdogan $T$, et al. International Validation of the Turkish Inappropriate Medication Use in the Elderly (TIME) Criteria Set: A Delphi Panel Study, Drugs Aging 2021; Apr 13:1-9, (PMID: 33847948). 